\title{
APROPOS "NEW VACCINES FOR DEVELOPING COUNTRIES: WILL IT BE FEAST OR FAMINE?
}

To the Editor:

We agree with Andrus et $\mathrm{al}^{1}$ for innovative financial mechanisms to finance vaccines for human papilliomavirus infection, rotavirus and pneumococcal disease in Latin America and the Caribbean. Involvement of masses along with linkage of such vaccinations to important individual events and/or other occasions for celebrations should emerge as an alternative.

For infants and young children, such immunization could be linked to the birthday of the individual. Parents or close relatives and family friends could be encouraged to consider such immunizations as an important birthday gift for their children. Moreover, elderly with grandchildren could be reciprocated with vaccine shots as an annual gift. Parents' day, mother's day or the celebration of a wedding anniversary such as a golden or diamond jubilee would be ideal. Events such as Christmas and New Year's Day do imply a festive atmosphere in Latin American countries and the Caribbean. Local supermarkets offer several incentives to customers to purchase gifts. There is often a discount on innumerable items for the customers. During such events, manufacturers of vaccines for human papilliomavirus infection, rotavirus and pneumococcal disease could plan innovative strategies intended to increase sale of these products. Attractive discounts could be offered to stimulate masses to receive annual dose of different vaccines.

Last but not least, any fiscal input from the local community in Latin America and the Caribbean region would orchestrate future input to the PAHO revolving Fund for new generation of vaccines. ${ }^{2}$

ARYA, Subhash C.

AGARWAL, Nirmala

Sant Parmanand Hospital

18 Alipore Road

Delhi-110054

Email subhashbhapaji@gmail.com

${ }^{1}$ Jon Kim Andrus et al., Ner Vaccines for Developing Countries: Will it be Feast or Famine?, 35 Aм. J.L. \& Med. 311 (2009).

${ }^{2} I d$. 